\title{
ANALISIS KEBUTUHAN WANITA KARIR DI BIDANG PENDIDIKAN ERA MILLENIAL
}

\author{
Anaway Irianti Mansyur ${ }^{1}$, Dede Rahmat Hidayat ${ }^{2}$ \\ Email: wayirianti@gmail.com ${ }^{l}$ \\ Pasca Sarjana Bimbingan dan Konseling, Universitas Negeri Jakarta, Indonesia ${ }^{1,2}$
}

\begin{abstract}
Abstrak
Artikel ini bertujuan untuk mendeskripsikan kebutuhan wanita karir khusunya bidang pendidikan di era milenial. Teknologi yang terus berkembang memberikan dampak pada wanita karir dalam menghadapi tantangan pekerjaan dan keluarga. Untuk meningkatkan kinerja, wanita karir membutuhkan skill dan keterampilan yang disesuaikan dengan kemajuan teknologi. Disisi lain, wanita karir juga memiliki tantangan dalam mengurus keluarga terutama dalam mendidik karakter anak. Wanita karir memiliki peran yang strategis dalam mendorong pembangunan yakni sebagai manajer rumah tangga, sebagai pelaku ekonomi dan sebagai perempuan karir. Artikel ini juga menganalisis tantangan yang dihadapi wanita karir dalam melaksanakan perannya di era milenial.
\end{abstract}

Kata Kunci: Wanita Karir; Era Milenial; Analisis Kebutuhan

PENDAHULUAN

Perkembangan karir semua wanita terjadi dalam konteks budaya tertentu seperti nilai-nilai, kebiasaan, dan norma sosial yang mengirim pesan implisit terkait dengan wanita dan gender (Cook, Heppner, \& O’Brien, 2005). Sebagian besar wanita karir mempertimbangkan bagaimana cara memperkuat hubungan dan membangun kepercayaan di lingkungan pekerjaan (Sökjer-Petersen \& Thorssell, 2008). Selain itu, wanita karir juga memiliki ketergantungan terhadap lingkungan sosialnya (Mozahem, Ghanem, Hamieh, \& Shoujaa, 2019). Berdasarkan penelitian yang dilakukan Danhauer, et.al.(2019) wanita karir mencari program pengembangan untuk menambah keterampilan agar dapat meraih kesuksesan dalam memajukan karir mereka. Sehingga, wanita karir membangun jaringan kolega dan mengurangi isolasi serta melakukan identifikasi terhadap potensi diri. Analisis terkait pengembangan wanita karir juga dilakukan di wilayah Amerika Utara dan Eropa (Madsen, 2012). Sedikit perhatian telah diberikan kepada pengembangan wanita karir di negara-negara Timur Tengah, khususnya di Arab Saudi. Studi yang tersedia saat ini sebagian besar berfokus pada tantangan dan dalam manajemen umum pada wanita karir. Hal ini dapat ditelaah dari hasil penelitian Tlaiss dan Khalil (2015) memfokuskan pekerjaan wanita karir pada pelatihan profesional dan kesempatan belajar bagi wanita. Serta menunjukkan bagaimana diskriminasi organisasi dan budaya bias gender dan adanya pengaruh ketegangan wanita di Lebanon. 
Abalkhail dan Allan (2015) memandang dukungan informal yang diberikan oleh keluarga merupakan salah satu proses perkembangan karir bagi wanita dan Abalkhail (2019) menyatakan bahwa wanita karir memiliki beberapa tantangan yang dihadapi ketika menjadi seorang pemimpin. Menurut Makrufi (2018) wanita karir memiliki faktor-faktor yang mempengaruhi motivasinya bekerja seperti kemajuan dan keanekaragaman dunia pendidikan sesuai dengan jenjang dan pemerataan antara wanita dan pria. Selanjutnya kebutuhan wanita untuk meningkatkan pelayanan di sector tertentu. Kemajuan di bidang transportasi yang membutuhkan tenaga dari wanita. Adapula permasalahan finansial yang mengharuskan wanita karir membantu ekonomi keluarga. Wanita yang terjun kedalam dunia karir, dihadapkan pada sebuah pilihan ketika sudah berkeluarga. Mereka dituntut untuk bersikap professional tetapi juga harus bisa mengurus keluarga. Karena faktor-faktor pribadi juga mendorong wanita untuk selalu berkembang. Sehingga wanita karir harus mengalami momen kritis di mana dalam kehidupan mereka memisahkan diri dari keluarga. Berdasarkan hasil wawancara yang dilakukan Ayre, Mills dan Gill (2013) menemukan bahwa wanita mengalami isolasi dan marginalisasi dalam budaya rekayasa maskulin. Namun, pada penelitian tersebut menjelaskan bahwa meskipun karir mereka tidak didukung oleh lingkungan sekitar tetapi mereka percaya diri sebagai seorang engineering. Dalam penelitian Simpkins, et.al. (2012) menemukan bahwa ada kecendurangan hambatan bagi wanita karir di bidang engineering terkait masa depan mereka untuk memiliki keluarga. Seharusnya ketimpangan ini tidak terjadi karena hadirnya globalisasi dan majunya teknologi. Karena menurut Yang (2014) karir dan pendidikan menjadi arena dimana wanita dapat mengeksplorasi aktualisasi diri.

Pendidikan dilihat sebagai kunci untuk memperbaiki posisi wanita dalam karir dan dalam keluarga. Di era revolusi industri 4.0 peningkatan kualitas dari sumber daya manusia dibutuhkan seiring dengan kebutuhan tenaga kerja di berbagai bidang. Menariknya sumber daya manusia memiliki peranan penting di dalam suatu negara karena merupakan modal dasar dari kekayaan suatu bangsa (Hasiani., 2015). Manusia adalah faktor produksi yang bersifat aktif mengumpulkan modal, mengeksploitasi sumber-sumber daya alam, membangun organisasi-organisasi sosial, ekonomi, politik dan melaksanakan pembangunan nasional. Peningkatan sumber daya 
manusia dapat dikembangkan dengan tujuan untuk mewujudkan manusia pembangunan yang berbudi luhur, tangguh, cerdas, terampil, mandiri, produktif, kreatif, inovatif, disiplin dan orientasi ke masa depan (Wakerkwa, 2016). Berkaitan dengan inovatif, perkembangan dinamis dalam bidang teknologi semakin memudahkan masyarakat khususnya generasi milenial untuk mengakses banyak informasi. Salah satu cara meningkatkan kualitas sumber daya manusia melalui pendidikan. Dengan pendidikan, seseorang bukan hanya belajar untuk mendapatkan ilmu secara teori tetapi juga mampu meningkatkan pemahaman isu-isu global seperti pembangunan berkelanjutan, politik, perdamaian, dan hak asasi manusia. Terlebih adanya dampak perkembangan Teknologi Informasi dan Komunikasi (TIK) memberikan pengaruh terhadap proses pembelajaran. Kemudian, komunikasi sebagai media pendidikan dilakukan dengan menggunakan media seperti media sosial, telepon, komputer dan internet. Untuk mendapatkan ilmu dari berbagai bidang, masyarakat dapat melakukannya dengan menggunakan internet.

Kemajuan teknologi merupakan sesuatu hal yang tidak bisa dihindari dalam kehidupan ini karena hadirnya kemajuan teknologi akan berjalan sesuai dengan kemajuan ilmu pengetahuan (Ngafifi, 2014). Kemudahan dalam mengakses informasi melalui teknologi memberikan kesempatan bagi penggunannya untuk berkembang di dalam setiap bidang ilmu Karena pendidikan ini dapat mempengaruhi tingkat kebebasan dan kemandirian wanita kearah positif. Sudah menjadi pengetahuan bersama bahwa pendidikan yang humanis memberikan kebebasan yang luas untuk berpikir kritis. Untuk itulah penelitian dilakukan agar dapat mengidentifikasi kebutuhan wanita karir di bidang pendidikan di era millennial.

\section{METODE PENELITIAN}

Penelitian ini menggunakan systematic review untuk mengidentifikasi penelitian yang relevan (Hariyati, 2010). Data yang terdiri dari kesaksian pengguna-layanan secara eksklusif diambil dari tujuh studi yang menganalisis terkait wanita karir di bidang pendidikan. Selain itu, systematic review adalah apa yang dikatakan kemudian dilakukan tinjauan literatur yang sistematis (Dixon, Agarwal, Jones, Young, \& Sutton, 2005). Secara historis, penelitian kualitatif adalah ulasan sistematis dari tinjauan literatur untuk meneliti konteksnya, dengan materi yang relevan diambil dari berbagai disiplin ilmu dan profesi. Dibawah ini 
adalah tabel check list untuk melakukan systematic review.

Tabel 1. Daftar check list untuk melakukan systematic review

\begin{tabular}{|c|}
\hline Pendahuluan \\
\hline $\begin{array}{l}\text { Tinjauan literatur kontekstual secara } \\
\text { singkat } \\
\text { Pertanyaan penelitian/tujuan penelitian }\end{array}$ \\
\hline Metodologi \\
\hline $\begin{array}{l}\text { Prosedur pencarian } \\
\text { Kriteria kelayakan: inklusi dan eksklusi } \\
\text { Ekstrasi Data } \\
\text { Kriteria dan Penilaian Kualitas } \\
\text { Sintesis Data } \\
\text { Pertimbangan Etis } \\
\end{array}$ \\
\hline Results/Findings \\
\hline $\begin{array}{l}\text { Alur studi } \\
\text { Karakteristik studi } \\
\text { Kualitas studi yang disertakan } \\
\text { Sintesis data }\end{array}$ \\
\hline Discussion \\
\hline $\begin{array}{l}\text { Meninjau kembali pertanyaan penelitian } \\
\text { Diskusi sehubungan dengan penelitian } \\
\text { sebelumnya } \\
\text { Keterbatasan ulasan } \\
\text { Penemuan masa depan } \\
\text { Implikasi / rekomendasi } \\
\text { Kesimpulan }\end{array}$ \\
\hline
\end{tabular}

Sumber: (Dixon et al., 2005)

Dari tabel diatas menunjukkan bahwa dalam penelitian ini untuk melakukan systematic review dibutuhkan ketelitian menganalisis hasil penelitian dari berbagai jurnal yang tersedia pada Garuda, Sage Publication, Taylor \& Francis, Emerald dan Science Direct.

\section{HASIL DAN PEMBAHASAN}

Dari 50 artikel yang ditemukan dengan kata kunci wanita karir, pendidikan dan era millennial hanya ada tujuh artikel yang sesuai dengan konsep penelitian systematic review dibawah ini yaitu: Judul: Development of an Innovative career development program for early-career women faculty. Global Advances in Health and Medicine (Danhauer et al., 2019). Hasil: Sebagian besar keterampilan menunjukkan peningkatan signifikan sebelum dan sesudah. Peningkatan terbesar terjadi dalam mengetahui jalur menuju promosi, menyesuaikan gaya komunikasi, kemampuan mengelola konflik, dan kemampuan menangani keseimbangan peran pribadi-profesional. Dalam penelitian ini, wanita karir melaporkan peningkatan signifikan untuk semua item yang mengukur kepercayaan diri. Secara keseluruhan, 89,3\% responden menilai dampak program sangat kuat / mendalam, 98,5\% menilai konsep itu penting, 95,2\% menilai keterampilan itu penting, dan 90,8\% menilai rasa kebersamaan dengan sesama wanita di kelas mereka sangat dekat

Judul: Feeling Precarious: Millennial Women and Work. Environment and Planning D: Society and Space. (Worth, 2016). Hasil: Menggunakan narasi ketidaknyamanan wanita milenial di tempat kerja, artikel ini bertujuan untuk memperluas pemahaman kita tentang pekerjaan yang tidak menentu melalui perhatian pada interdependensi dan otonomi relasional. Prekariat 
merupakan pekerja yang berdapa pada kondisi rentan. Hasil penelitian ini menunjukkan bahwa wanita di working lives memiliki perasaan kewaspadaan dan berdampak terhadap pengelaman kerja yang aman secara objektif di mata mereka. Sehingga mereka meragukan diri sendiri untuk mendapatkan pekerjaan di bidangnya.

Judul: Career Development of Women in Academia: Traversing the Leaky Pipeline. The Professional Counselor.(Gasser \& Shaffer, 2014). Hasil: Pengalaman wanita karir di dunia akademis sarat dengan serangkaian masalah mendasar yang berkaitan dengan ketidaksetaraan gender. Sebuah model yang mencerminkan pengembangan karier dan pengalaman wanita di sekitar jalur akademis mereka (atau karier di akademisi). Model ini selanjutnya menyampaikan perspektif baru tentang pengalaman akademisi wanita sebelum, selama dan setelah masuk dalam fakultas dan dapat membantu dalam konseling karir. Secara khusus, model ini memberikan konselor karir dengan kerangka kerja untuk mengonseptualisasikan keprihatinan klien wanita yang bekerja di lingkungan akademik.

Judul: Women at Work: How Organizational Features Impact Career
Development. Work and Organizations (Ellemers, 2014). Hasil: $\quad$ Kunci untuk benar-benar memberikan peluang karir yang setara untuk pria dan wanita dalam organisasi dalam penelitian ini ini sulit dicapai, karena bias gender implisit. Hal ini memungkinkan orang dalam organisasi untuk memeriksa dan mengoreksi kebijakan dan praktik yang tanpa disadari dapat melanggengkan kesenjangan gender saat ini atau memperkuat bias implisit. Perilaku sains menunjukkan bahwa beberapa solusi akal sehat mungkin kontraproduktif, dan ungkapkan intervensi mana paling mungkin efektif. Wawasan dari ilmu perilaku beri tahu kami tentang apa yang dapat dilakukan untuk membantu wanita "bersandar"; pilihan kebijakan tertentu akan tergantung pada yang paling mendesak prioritas organisasi.

Judul: The Career Development of Recently Qualified British South Asian Women teachers: "Everybody's the same. I don't feel my ethnicity is an issue at all". Educational Review (Butt, MacKenzie, \& Manning, 2012). Hasil: Penelitian ini menunjukkan guru wanita keturunan British South Asian pada awal karir, mereka mampu menghadapi, dan mengatasi peluang dan tantangan yang serupa dengan guru pemula lainnya. Meskipun beberapa ketegangan tertentu didasari oleh pekerjaan, keluarga, dan 
kondisi lingkungan para guru, Namun mereka berhasil memantapkan diri sebagai individu yang dihormati, mampu menyeimbangkan komitmen profesional dan pribadi mereka dengan terampil.

Judul: Career Development and Counselling for Women: Connecting Theories to Practice. Counseling Psychology Quarterly (Coogan \& Chen, 2007). Hasil: Pengembangan karir wanita lebih kompleks daripada laki-laki karena berbagai hambatan internal dan eksternal, termasuk orientasi peran gender, ketidakadilan dalam pekerjaan, dan tanggung jawab keluarga, yang menyulitkan dan membatasi pilihan dan kemajuan karier wanita. Beberapa konsep kunci dari karier teori pengembangan Gottfredson, Super, dan SCCT tampaknya berlaku untuk masalah pengembangan karir wanita. Dipandu oleh model teoritis ini, peneliti telah mengusulkan sejumlah pertimbangan konseling karir yang ditujukan khusus untuk membantu klien wanita. Pertimbangan ini dimaksudkan untuk menghubungkan teori dan berlatih dalam konteks pengembangan karir wanita, suatu bidang yang masih harus dilakukan dan dipelajari lebih lanjut untuk diperkaya dalam bidang psikologi kejuruan dan karier.

Judul: Effect of Career Development on the Organizational
Commitment and Life Satisfaction of Women Student Affairs Administrators. NASPA Journal (Blackhurst, Brandt, \& Kalinkowski, 1998). Hasil: Penelitian ini melakukan kerjasama dengan mahasiswa wanita di bidang administrator dengan melakukan evaluasi melalui uji hubungan antara pengembangan karir, komitmen organisasi, dan kepuasan hidup. Secara khusus, penulis menganalisis pengaruh usia, posisi judul, pencapaian pendidikan, tahun bekerja dan tahun di posisi saat ini. Hasil menunjukkan hubungan yang signifikan antara variables pengembangan karier dan kedua operasional seperti komitmen dan kepuasan hidup.

Dalam perspektif historis, penulis membahas simbolisasi sosok wanita dalam imajiner sosial ada kaitannya dengan karier mengajar, berdasarkan praktik pelatihan guru, profesionalisasi dan pendidikan. Sejak zaman kolonial, pendidikan wanita di Brasil selalu dipenuhi dengan harapan tentang tugas domestik yang menjadi peran utama wanita (Nicolete, \& Almeida, 2017). Namun, wanita karir yang memilih di bidang pendidikan mengalami banyak tantangan yang tidak terduga. Pada umumnya pengukuhan dikotomi peran antara pria dan wanita melalui sosialisasi yang terus-menerus dalam keluarga, sekolah, agama dan negara sehingga 
dirasakan sebagai suatu kebenaran baku yang harus diterima begitu saja. Dilihat dari hasil analisis yang dilakukan oleh Danhauer (2019) terkait program pengembangan karir untuk wanita sangat dibutuhkan. Meskipun pada kenyataan sosial, wanita dibentuk sebagai pribadi yang lembut, tidak asertif, dan cenderung mengalah tidak menutup semangat mereka dapat percaya diri bekerja sama dengan pria. Dari hasil penelitian Danhauer program yang dilakukan untuk mengembangkan karir pada wanita mampu meningkatkan pemahaman yang baik tentang bagaimana bekerja secara efektif dengan orang yang memiliki perbedaan gaya dalam bekerja. Selain itu, mereka mampu menghadapi perasaan yang saling bertentangan dalam upaya menyeimbangkan peran pribadi dan professional. Sejak tahun 1998, pengembangan karir pada perempuan terus dianalisis untuk menemukan kebutuhan yang sesuai. Salah satunya adalah Balckhurst yang melakukan penelitian terkait efek pengembangan karir tentang komitmen organisasi dan kepuasan hidup mahasiswa wanita di bidang administrasi. Dibutuhkan mentoring untuk meningkatkan kepercayaan diri dan kepuaasan hidup pada mahasiswa perempuan sebagai langkah menjadi wanita karir.
Pada penelitian Butt menemukan bahwa wanita karir keturunan British South Asian di Inggris yang memilih dibidang pendidikan memberikan persepsi kecocokan pada mengajar dengan kehidupan keluarga. Karena dengan karir mengajar mereka mampu menyeimbangkan kehidupan kerja yang dirasakan. Meskipun pada kenyataanya mereka mengalami diskriminasi etnis. Berhubungan dengan wanita karir di bidang pendidikan, sebagai konselor wanita juga harus mampu mengetahui berbagai sumber informasi dan tren millennial yang sesuai dengan kemajuan teknologi. Seperti yang sudah diteliti oleh Coogan dan Chen mnejelaskan bahwa konselor harus belajar berfungsi sebagai fasilitator yang peka, seorang pendidik yang berpengetahuan luas, seorang konsultan yang banyak akal, dan advokat yang konstruktif tentang masalah pengembangan karir wanita. Disisi lain, wanita karir juga harus memiliki koneksi yang baik, pengembangan kepemimpinan dan program pendidikan tinggi untuk menunjang karirnya.

Dari data diatas menunjukkan bahwa dari berbagai latar belakang wanita karir di bidang pendidikan, untuk meningkatkan kinerjanya mereka membutuhkan pemahaman terkait berbagai komunikasi dan penggunaan teknologi. Hal ini tidak 
hanya berlaku pada wanita yang sedang menjalani karirnya tetapi juga yang akan memilih untuk berkarir.

\section{Profesionalitas Wanita Karir}

Menurut Pane (2018) wanita karir adalah wanita yang bekerja, baik dibidang profesi yang menghendaki persyaratanpersyaratan tertentu maupun pekerjaan yang tidak menuntut adanya persyaratan tertentu guna mengembangkan diri untuk mendapatkan kemajuan. Sejalan Ana Septia Rahman (2017) dengan Wanita karier adalah wanita yang berpendidikan tinggi dan mempunyai status yang tinggi dalam pekerjaannya, yang berhasil dalam berkarya yang dikenal sebagai wanita bekerja atau wanita berkarya. Disisi lain, Sunarsih, Zain dan Umar(2018) menyatakan bahwa wanita karir merupakan wanita yang menuntut adanya ketrampilan tertentu untuk dapat mengembangkan diri dalam mencapai kemajuan. Sehingga Keterlibatan kaum wanita yang semakin tinggi menimbulkan peran ganda wanita. Peran tersebut yaitu peran di dalam rumah tangga dan peran di luar rumah. Untuk itu, wanita karir harus mampu menyimbangkan bekerja di luar tapi tetap memperhatikan pola asuh dalam pendidikan anak-anaknya.

Kebutuhan yang timbul pada wanita untuk bekerja adalah sama seperti pria, yaitu kebutuhan psikologis, rasa aman, sosial, ego, dan aktualisasi diri. Bagi diri wanita itu sendiri sebenarnya dengan bekerja di luar rumah, ia akan mencapai suatu pemuasan kebutuhan. Pada hakekatnya sinonim kata wanita dan perempuan itu sama saja namun dalam perkataan (perempuan) lebih halus, akan tetapi dalam skripsi ini untuk selanjutnya penulis gunakan kata "wanita" dimaksudkan karena wanita adalah istilah yang lebih populer dan lebih banyak disebutkan dalam percakapan sehari- hari. Pengertian wanita dalam kamus besar bahasa Indonesia wanita adalah perempuan dewasa atau kaum puteri. Membicarakan wanita karier, mereka yang berorientasi didunia karier memandang keberhasilan kerja tidak hanya diukur dengan capaian materi semisal gaji atau upah melainkan juga ditentukan oleh prestasi kerja yang pada gilirannya mengantarkan individu ke jenjang tertinggi dalam organisasi ataupun prestige lainnya.

Wanita dalam meniti karier masih dipandang sebagai kelompok wanita, belum banyak yang memandang sebagai pribadi manusia yang mempunyai kemampuan tertentu. Tentu saja hal itu juga akan menghambat cita-cita wanita karier, karena dalam meniti karier selalu menoleh ke belakang. Wanita selalu mendengarkan penilaian masyarakat yang 
tak jarang memberi nilai negatif, karena tidak bekerja sesuai dengan kodrat wanita. Seolah-olah tugas wanita sudah dikondisikan tertentu, dan buruk bagi wanita yang keluar dari kondisi yang ditentukan tersebut. Menurut Flanders (dalam Mudzhar 2001) wanita karir dibedakan menjadi tiga kategori, yaitu:

a. Wanita tunggal dan tidak memiliki anak. Dalam rangka mengembangkan karir ada beberapa wanita yang memilih untuk tidak menikah terutama pada usia 20-an dan awal 30. Tetapi kebanyakan melakukan hal tersebut bukan semata-mata agar tidak mengalami hambatan dan rintangan dalam karir mereka melainkan karena merasa pilihan tersebut cocok dengan pribadi mereka.

b. Wanita menikah tanpa anak. Wanita karier yang menikah tanpa anak memiliki pasangan yang saling mendukung dan membantu dalam urusan rumah tangga. Mereka tidak terlalu bermasalah dalam hal keuangan karena adanya pemasukan dari pihak suami dan juga pihak istri, serta belum/tidak mempunyai anak yang dapat 11 menyita waktu dan tenaga yang dapat mengurangi kinerja atau prospek karirnya. c. Wanita menikah dan mempunyai anak dengan perencanaan keluarga yang baik dan kesempatan untuk memperoleh pendidikan serta pekerjaan yang semakin terbuka bagi wanita, maka seorang wanita akan menggabungkan peran mereka dalam pekerjaan di tempat kerja serta peran mereka sebagai ibu rumah tangga di rumah.

Dengan wanita menggabungkan peran mereka dalam pekerjaan dan sebagai ibu dan istri dalam rumah tangga, secara otomatis akan menghadapkan wanita dengan berbagai masalah, seperti: Peningkatan tanggung jawab yang menyita waktu dan menimbulkan stress fisik serta emosional, Rasa bersalah karena kurang dapat memberikan perhatian dan waktu pada anak atau pekerjaan, Kesempatan karir yang terbatas karena sikap atasan yang meragukan komitmen terhadap keluarga. Dengan demikian ada beberapa persyaratan yang harus dipenuhi oleh seorang wanita yang ingin berkarier (Prabuningrat, 1993) dalam (Ermawati, 2016);

1. Memiliki kesiapan mental wanita karier harus memiliki wawasan tentang bidang yang digelutinya dan memiliki keberanian memikul tanggung jawab sehingga tidak bergantung pada orang lain. 
2. Kesiapan jasmani wanita karier harus sehat secara fisik dan memiliki stamina untuk menekuni bidang pekerjaan tertentu.

3. Kesiapan sosial seorang wanita karier harus memiliki kemampuan untuk; (a) mengembangkan keharmonisan hubungan antara karier dan kegiatan rumah tangga, (b) menumbuhkan saling pengertian dengan keluarga dekat dan tetangga, (c) mengontrol pergaulan yang luas dengan cara menjaga martabat diri sehingga terhindar dari fitnah dan gosip, dan (d) beradaptasi dengan lingkungan terkait.

4. Memiliki kemampuan untuk selalu meningkatkan prestasi kerja demi kelangsungan karier di masa depan.

5. Menggunakan peluang dan kesempatan yang baik. 6 . Mempunyai pendamping yang mendukung dengan gagasan baru

Ada tiga peran wanita pada zaman sekarang ini yaitu (Alexandra Dewi dalam buku Melly, 2008) dalam (Rosita, 2012): 1) sebagai istri, 2) sebagai ibu, 3) sebagai wanita karir. Peran ganda wanita sebagai istri, ibu dan sebagai pekerja atau wanita karir menuntut upaya ekstra dari si wanita agar dapat menjalankan peran-peran tersebut secara seimbang dan optimal.
Seorang wanita harus bisa menjadi seorang yang super, sukses didalam keluarga sebagai diri sendiri, istri, ibu, domestik manager dan sukses juga diluar rumah sebagai ibu bekerja, wanita karir ataupun anggota organisasi kemasyarakatan lainnya. Sehingga peran ganda dari wanita karir ini membutuhkan kesiapan mental yang baik.

\section{KESIMPULAN}

Wanita karir dituntut untuk bersikap professional dalam sebuah pekerjaan. Namun, wanita yang memilih berkarir harus menyesuaikan dengan teknologi yang terus berkembang pesat. Dengan wanita menggabungkan peran mereka dalam pekerjaan dan sebagai ibu dan istri dalam rumah tangga, secara otomatis akan menghadapkan wanita dengan berbagai masalah, seperti: Peningkatan tanggung jawab yang menyita waktu dan menimbulkan stress fisik serta emosional, Rasa bersalah karena kurang dapat memberikan perhatian dan waktu pada anak atau pekerjaan. Sehingga dibutuhkan kesiapan mental bagi wanita yang memilih untuk berkarir. Selain itu, untuk membantu pengembangan wanita karir konselor wanita juga harus memiliki informasi terkait permasalahan yang dialami wanita karir di era milenial.

\section{REFERENSI}

Abalkhail, J. M. 2019. Women's career 
development in an Arab Middle Eastern context. Human Resource Development International, 22(2), 177-199.

https://doi.org/10.1080/13678868.20 18.1499377

Abalkhail, J. M., \& Allan, B. 2015.

Women's career advancement:

Mentoring and networking in Saudi

Arabia and the UK. Human Resource

Development International, 18(2),

153-168.

https://doi.org/10.1080/13678868.20

15.1026548

Ayre, M., Mills, J., \& Gill, J. 2013. 'Yes, I do belong': The women who stay in engineering. Eng. Stud., 5(3), 216232.

Blackhurst, A. E., Brandt, J. E., \& Kalinkowski, J. 1998. Effects of Career Development on the Organizational Commitment and Life Satisfaction of Women Student Affairs Administrators. Journal of Student Affairs Research and Practice, 36(1), 19-34. https://doi.org/10.2202/19496605.1067

Butt, G., MacKenzie, L., \& Manning, R. 2012. The career development of recently qualified British South Asian women teachers:

"Everybody's the same. I don't feel my ethnicity is an issue at all."

Educational Review, 64(2), 181-194. https://doi.org/10.1080/00131911.20 11.598915

Coogan, P. A., \& Chen, C. P. 2007. Career development and counselling for women: Connecting theories to practice. Counselling Psychology Quarterly, 20(2), 191-204. https://doi.org/10.1080/09515070701 391171

Cook, E. P., Heppner, M. J., \& O’Brien,
K. M. 2005. Multicultural and gender influences in women's career development: An ecological perspective. Journal of Multicultural Counseling and Development, 33(3), 165-179. https://doi.org/10.1002/j.21611912.2005.tb00014.x

Danhauer, S. C., Tooze, J. A., Barrett, N. A., Blalock, J. S., Shively, C. A., Voytko, M. Lou, \& Crandall, S. J. 2019. Development of an Innovative Career Development Program for Early-Career Women Faculty. Global Advances in Health and Medicine, 8, 216495611986298.

https://doi.org/10.1177/21649561198 62986

Dixon, W. M., Agarwal, S., Jones, D., Young, B., \& Sutton, A. 2005. synthesising qualitative and quantitative evidence: A review of possible methods. Journal of Health Services Research \& Policy, 10(1), 45-55.

Ellemers, N. 2014. Women at Work: How Organizational Features Impact Career Development. Policy Insights from the Behavioral and Brain Sciences, 1(1), 46-54. https://doi.org/10.1177/23727322145 49327

Gasser, C. E., \& Shaffer, K. S. 2014. Career Development of Women in Academia: Traversing the Leaky Pipeline. The Professional Counselor, 4(4), 332-352. https://doi.org/10.15241/ceg.4.4.332

Hariyati, R. T. S. 2010) Mengenal Systematic Review Theory dan Studi Kasus. Jurnal Keperawatan Indonesia, 13(2), 124-132. https://doi.org/10.7454/jki.v13i2.242

Hasiani., F. 2015 Analisis Kualitas Sumber Daya Manusia Dan 
Pengaruhnya Terhadap Pertumbuhan Ekonomi Di Kabupaten Pelalawan. Jom FEKON Vol., 2(2), 1-15.

Madsen, S. R. 2012. Women and leadership in higher education: Learning and advancement in leadership programs. Advances in Developing Human Resources, 14(1), 3-10. https://doi.org/10.1177/15234223114 29668

Makrufi, A. D. 2018. Peran wanita karir dalam pendidikan islam di era digital. Vicratina Jurnal Pendidikan Islam, 2(2), 10-25.

Mozahem, N. A., Ghanem, C. M., Hamieh, F. K., \& Shoujaa, R. E. 2019. Women in engineering: A qualitative investigation of the contextual support and barriers to their career choice. Women's Studies International Forum, 74(December 2018), 127-136. https://doi.org/10.1016/j.wsif.2019.0 3.014

Ngafifi, M. 2014. Kemajuan Teknologi Dan Pola Hidup Manusia Dalam Perspektif Sosial Budaya. Jurnal Pembangunan Pendidikan: Fondasi Dan Aplikasi, 2(1), 33-47. https://doi.org/10.21831/jppfa.v2i1.2 616

Simpkins, S. D., Fredricks, J. A., \& Eccles, J. S. 2012) Charting the
Eccles' expectancyvalue model from mothers' beliefs in childhood to youths' activities in adolescenc. Dev. Psychol, 48(4), 1019-1032.

Sökjer-Petersen, M., \& Thorssell, J. 2008. Women's view of trust and its influence on entrepreneurship and career development. Nordic Psychology, 60(2), 114-128. https://doi.org/10.1027/19012276.60.2.114

Tlaiss, H., \& D, K. 2015. "Women and Training: An Empirical Investigation in the Arab Middle East. Human Resource Development International, 18(4), 366-386.

Wakerkwa, O. 2016. Peranan Manusia Dalam Kabupaten Lanny Jaya Onius Wakerkwa. Jurnal Holistik, (17A), $1-22$.

Worth, N. 2016. Feeling precarious: Millennial women and work. Environment and Planning D: Society and Space, 34(4), 601-616. https://doi.org/10.1177/02637758156 22211

Yang, A. 2014. Themes in the Career Development of 1.5-Generation Hmong American Women. Journal of Career Development, 41(5), 402425.

https://doi.org/10.1177/08948453135 07775 